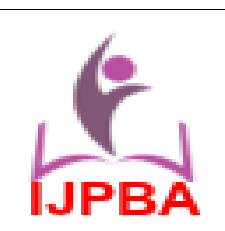

\author{
Contents lists available at www.ijpba.in \\ International Journal of Pharmaceutical and Biological Science Archive \\ PubMed (National Library of Medicine ID: 101738825) \\ Index Copernicus Value 2017: 71.80 \\ Volume 7 Issue 3; May-June; 2019; Page No. 105-108
}

\title{
METHOD DEVELOPMENT AND VALIDATION OF MESALAMINE IN PHARMACEUTICAL DOSAGE FORM: A REVIEW
}

\section{Shubhamkar Ashok Desai ${ }^{*}$, Prof R.N.Kale}

Department of Quality Assurance, SVPM'S College of Pharmacy Malegaon BK II (MS) India

Conflicts of Interest: Nil

Corresponding author: Shubhamkar Ashok Desai

\begin{abstract}
Anti-inflammatory agents are the important class of drugs used in various commercial pharmaceutical formulations for the treatment of fever, inflammation and minor pain. One of the important antiinflammatory drug is Mesalamine which belongs to the class of Amino-salicylic acid derivatives. Mesalamine is a bowel specific anti-inflammatory drug used in the treatment of inflammatory bowel diseases such as ulcerative colitis and Crohn's disease.it is available in different pharmaceutical dosage forms such as delayed release, extend release and enteric coated tablets and capsulesetc., The several of Mesalamine brand's available in market are Apriso, Asacol MR-400mg, Lialda, Pentasa-500mg, Asalosa- 800 etc. Hence routine quality control of Mesalamine in these pharmaceutical dosage forms requires effective analytical procedures. In this present review an extensive survey of research work published in various research journals has reviewed and found that various instrumental analytical methods were developed, validated and used for the estimation of Mesalamine in bulk drug and formulation. The developed analytical methods include Spectrometric such as Ultraviolet (UV) and Visible; Spectroflourimetric and Chromatographic methods such as High Performance Liquid Chromatographic (HPLC), Reverse Phase High Performance Liquid Chromatographic (RP-HPLC), Ultra Performance Liquid Chromatographic (UPLC)
\end{abstract}

Keywords: HPLC,Mesalamine,Anti-inflammatory, Method Development

\section{INTRODUCTION}

Mesalamine also known as mesalazine or 5-amino salicylic acid (5-ASA), is an anti-inflammatory drug used to treat inflammatory bowel disease, such as ulcerative colitis and mild-tomoderate Crohn's disease. Mesalamine is a bowel-specific amino salicylate drug that acts locally in the gut and has its predominant actions, thereby having few systemic side effects.

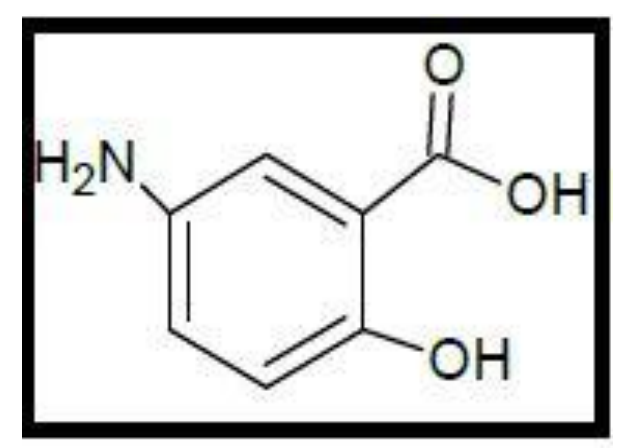

Figure 1: Structure of Mesalamine

As a derivative of salicylic acid, mesalamine is also thought to be an antioxidant that traps free radicals, which are potentially damaging byproducts of metabolism. Mesalamine is considered the active moiety of Sulfasalazine, which is metabolized to Sulfapyridine and Mesalamine. Literature survey revealed that a few analytical methods have been reported for the determination of mesalamine in pure drug, pharmaceutical dosage forms and in biological samples using spectrophotometry, HPLC, UPLC and LCMS either in single or in combined forms. Stability of pharmaceutical product may be defined as, the capacity of a particular formulation in a specific container or closure system, to remain within its physical, chemical, microbiological, therapeutic and toxicological specifications. Stability of a drug can also be defined as, the time from the date of manufacture and packing of the formulation until its chemical and biological activity is not less than a predetermined label of potency and its physical characteristics have not changed appreciably or deleteriously. The $\mathrm{ICH}$ guideline requires that stress testing be carried out to elucidate the inherent stability characteristics of the active substances. It is stated that testing should include the effect of temperature, humidity (where appropriate), oxidation, photolysis and susceptibility to hydrolysis across a wide range of $\mathrm{pH}$ values. An ideal stability indicating method is 
one that quantifies the drug per and also resolves its degradation products. ${ }^{[1,2,3]}$

Moharana AK et al., have reported a simple and cost effective spectrophotometric method for the estimation of Mesalamine in pure form and in pharmaceutical formulations. The absorbance value at $303 \mathrm{~nm}$ was used for the estimation of Mesalamine and obeyed Beer's law in the concentration range of $10-50 \mu \mathrm{g} / \mathrm{ml}[4]$.

Rao RN et al., have developed and validated an UV Spectrophotometric method for the determination of Mesalazine in pure and tablet dosage form. The solvent used was phosphate buffer with $\mathrm{pH} 6.8$ and maximum absorbance was found to be $330 \mathrm{~nm}$ [5].

Gatkal SH et al., have developed UV-visible spectrophotometric method for the kinetic degradation study of Mesalamine by dry heat degradation carried out at500,600,7000C. Distilled water was used as solvent. The concentration range was found to be $2-16 \mu \mathrm{g} / \mathrm{ml}$. The energy of activation was estimated as $0.05169 \mathrm{~J}$ oule $/ \mathrm{mol}$. This method showed high sensitivity with good I [6].

Sabha TNet al., have been a developed a simple, accurate and more sensitive spectrophotometric method for the determination of Mesalamine by using sodium nitroprusside as chromogenic agent which forms green coloured chromogen. The visible detection was carried out at $703 \mathrm{~nm}$. The linearitybconcentration range was found to be $0.0-$ $30 \mu \mathrm{g} / \mathrm{ml}$ with molar absorptivity of $2.0367 \times 104$ $\mathrm{l} / \mathrm{mol} / \mathrm{cm}$. The average recovery and $\%$ relative standard deviation were reported as $103.0 \%$ and $1.5 \%$ respectively [7].

Kanubhai TR et al., have reported gradient reverse phase UPLC method for thedetermination of Mesalamine related impurities from drug product. The chromatographic separation was done by employing BEH C18 column $(50 \mathrm{~mm} \times 2.1 \mathrm{~mm}$, $1.7 \mu \mathrm{m})$ using bgradient elution with the detection wavelength at $220 \mathrm{~nm}$. The flow rate, column oven temperature, injection volume optimized at $0.7 \mathrm{ml} / \mathrm{min}, 400 \mathrm{C}$ and $7 \mu \mathrm{l}$ respectively. The \%RSD value was reported as less than $2.0 \%$. The method was validated as per $\mathrm{ICH}$ guidelines and was successfully applied for quantification of impurities and degradation products in Mesalamine delayed released formulation [8]

Rafael et al., have developed HPLC, DPPH and Nitration methods for the determination of Mesalamine in pharmaceutical dosage form. The UV detection was carried out at $254 \mathrm{~nm}$ by using
C18 column using phosphate buffer of $\mathrm{pH} 7.0$ and methanol in the ratio $70: 30 \mathrm{v} / \mathrm{v}$ as mobile phase. The DPPH method was carried out at $517 \mathrm{~nm}$ using $100 \mathrm{mmol} / \mathrm{L}$ acetate buffer of $\mathrm{pH} 5.5$, ethanol and $250 \mathrm{mmol} / \mathrm{L}$ ethanolic solution of DPPH [9].

Zakaria RA, have developed two visible spectrophotometric methods for the estimation of Mesalazine in bulk drug and capsule formulations. The method A was based on the oxidative coupling reaction of Mesalazine with 8-hydroxy Quinazoline which exhibited absorption maxima at $644 \mathrm{~nm}$ within concentration range of $10-300 \mu \mathrm{g} / \mathrm{ml}$. However Method $B$ was based on the reaction of Mesalazine with $\mathrm{N}$-(1-napthyl) ethylenediamine which showed maximum absorption at $543 \mathrm{~nm}$. The $\%$ RSD was fund to be $\pm 1.31 \%- \pm 0.39 \%$ and $\pm 0.88 \%$ $- \pm 0.32 \%$ for methods A and B respectively [10].

Nobilis $\mathbf{M}$ et al., have developed HPLC method for the determination of Mesalamine and its metabolite in blood plasma. The chromatographic methods were developed by using $250.4 \mathrm{~mm}$ column containing purospher RP-18 e, $5 \mu \mathrm{m}$ with a pre-column $(4-4 \mathrm{~mm})$. The column effluent was monitored by employing UV photodiode array and fluorescence detector at the wavelength of $313 \mathrm{~nm}$ and $300 \mathrm{~nm}$ respectively. The flow rate was maintained at $1 \mathrm{~mL} / \mathrm{min}$. this validated HPLC method was applied to pharmacokinetic study of Mesalazine in human and animals [11].

Narala SR et al., have developed two different spectroscopic methods for the development and validation of Mesalamine in pharmaceutical preparation. Method A involved the formation of yellow colored chromogen by the reaction between Mesalamine and $p$ hydroxy benzaldehyde to form schiff's base which showed absorption maxima at $420 \mathrm{~nm}$ (concentration range; $8-28 \mu \mathrm{g} / \mathrm{ml}$ ). Method $B$ was based upon the reaction of Mesalamine with Folin ciocalteu phenol's reagent under alkaline condition forming blue colored chromogens which shows absorption maxima at $725 \mathrm{~nm}$ and obeyed Beer's law concentration range within $4-24 \mu \mathrm{g} / \mathrm{ml}$ [12].

Zadeh HA et al., have a developed spectroflourimetric method for the Determination of Mesalamine in human serum using solid phase extraction sorbent (SPE) for separation and pre concentration of trace amount of Mesalamine was assisted using column methodand the retained analyte was eluated with $\mathrm{NaOH}$ solution and the concentration of eluated mesalamine was then spectroflourimetrically determined at maximum 
wavelength $480 \mathrm{~nm}$ with excitation at $340 \mathrm{~nm}$.the limit detection and enrichment factor were 0.04 and $40 \mu \mathrm{g} / \mathrm{L}$ respectively. The relative standard deviation (RSD) resulting from analysis of six replicates $100 \mathrm{ml}$ solution containing $1.0 \mu \mathrm{g} / \mathrm{L}$ Mesalamine was $2.05 \%$. This optimized method was successfully applied to the determination of mesalamine in blood serum samples [13].

Reddy MP et al., have developed a quantitative estimation method for Mesalamine in bulk sample and its pharmaceutical dosage forms by two simple spectrophotometric methods. Method A was based upon the diazotization of primary amine group of mesalamine with sodium nitrite and concentrated $\mathrm{HCl}$ followed by coupling reaction with resorcinol to form orange coloured chromogens which shows absorption maximum absorption at $460 \mathrm{~nm}$. Method B was based on the reactions between mesalamine and vaniline in acidic medium producing schiff's base having absorption maxima at $395 \mathrm{~nm}$ [14].

Sama NS et al., have reported the spectrophotometric determination of Mesalamine in bulk and pharmaceutical preparations by adapting two methods ( $A$ and $B$ ). Method A was reported based on the reaction between mesalamine with 1, 2- Napthaquinone-4sulphonate (NQS) in the presence of $\mathrm{NaOH}$ which shows absorption maxima at $475 \mathrm{~nm}$. Simillarly Method B was developed based on the reaction between mesalamine with acidic solution of $p$ dimethyl amino cinnamaldehyde (PDAC) which forms reddish brown colour and was measured by UV spectrophotometerat $524 \mathrm{~nm}$. A linearity concentration range of $1.0-16.0 \mu \mathrm{g} / \mathrm{ml}$ was found for method $A$, also concentration range of 5$25.0 \mu \mathrm{g} / \mathrm{mlfor}$ method B. Percentage recovery of mesalamine was found to be $96.6 \%$ for method A. and $98.0 \%$ for method B respectively. However Percentage RSD value was reported as $0.4177 \%$ and $0.395 \%$ formethod $A$ and $B$ respectively [15]

Darak VR et al., have developed three colorimetric methods for the determination of Mesalamine in bulk drug and pharmaceutical preparations. The absorption maxima for the methods $A$ and $B$ were found to be $510.5 \mathrm{~nm}$ and $522.5 \mathrm{~nm}$ with concentration range of $210 \mu \mathrm{g} / \mathrm{ml}$ respectively based on the oxidation reaction of Mesalamine followed by complexation of iron with 1,10phenanthroline, 2,2 bipyridine which forms red chromogens. The method $C$ was based upon reaction between Mesalamine with B-Methyl benzothiazolinonehydrate which form green colored chromogen which shows absorption maxima at $586.8 \mathrm{~nm}$ with concentration range of 4$20 \mu \mathrm{g} / \mathrm{ml}[16]$.

Reddy KS et al., have reported simple, precise and accurate RP HPLC assay method for the estimation of Mesalamine in bulk and its tablet dosage form. The mobile phase used composed of mixed buffer and acetonitrile $(65: 35 \mathrm{v} / \mathrm{v})$ required for effective separation using waters HPLC C18, $100 \times 4.6,5 \mu$ column with a flow rate of $1.0 \mathrm{ml} / \mathrm{min}$ for UV detection at $258 \mathrm{~nm}$. The retention time for Mesalamine was found to be $3.214 \mathrm{mins}$ within the concentration range of $10-60 \mu \mathrm{g} / \mathrm{ml}$ with a correlation co-efficient 0.998 . The proposed method was validated as per $\mathrm{ICH}$ guidelines and successfully applied for routine analysis of Mesalamine in bulk samples and its formulations [17].

Rao KH et al., have developed and validated RPHPLC method for the estimation of Mesalamine in bulk and tablet dosage form using Xterra ODS C18 ( $250 \mathrm{~mm} \times 4.6 \mathrm{~mm}$ I.D., $5 \mu \mathrm{m}$ particle size) column at ambient temperature. The UV detection was carried out at $235 \mathrm{~nm}$ with a flow rate of $20 \mu \mathrm{L}$. The mobile phase used was composed of phosphate buffer $\mathrm{pH}$ 6.8: methanol $(60 ; 40, \mathrm{v} / \mathrm{v})$. The retention time was found to be $2.172 \mathrm{~min}$ and the percentage recovery was reported within the range of $98.0 \%$ and $101.3 \%$ [18].

\section{Reference}

1. www.drugbank.ca /drugs /DB00244.

2. Sama NS, Gurupadayya BM, Kumar CA. J. Pharm. Res., 2011; (1): pp 39-41.

3. www.rxlist.com /Lialda-drug / clinical pharmacology, html.

4. Moharana AK, Banerjee M, Panda S, Muduli JN. Int. J. Pharm. Sci., 2011; 3(2): pp 19-21.

5. Rao RN, Reddy LS, Reddy EP, Ravisankar Sulakshana S, Meenakshi R. Int. J. Pharm. Res. Sch., 2015; 4(4): pp 88-92.

6. Gatkal SH, Chopade VV, Mhatre PR, Chaudhari PD. Int. J. Pharm. Chem. Sci., 2013; 2(2): pp 978-981.

7. Sabah TN, Habeeb NN. Eur. Chem. Bull., 2015; 4(8): pp 384- 388.

8. Kanubhai TR, Muresh CP, Amith RK. J. of Chem., 2011; 8(1): pp 131-148.

9. Rafael JR, Jabor JR, Casagrande R, Georgetti $S R$, Borin MF, Fonseca MJV. Braz. J. Pharm. Sci., 2007; 43(1): pp 97-103. 
10. Zakariya RA. J. Raf. Sci., 2013; 24(1): pp 146158.

11. Nobilis M, Vybiralova Z, Sladkova $K$, Lisa $M$, Holcapek M, Kvetina J. J. Chromatogr. A., 2006; 11(19): pp 299-308.

12. SR. Narala, K. Saraswathi. J. Chem. Pharm. Res., 2011; 3(1): 784-787.

13. Zadeh HA, kohansal S. J. Braz. Chem. Soc., 2012; 23(3).
14. Reddy MP, Prabhavathi P, Reddy NR, Reddy R. Global Pharmacol., 2011; 5(2): pp 101-105.

15. Sama NS, Gurupadayya BM, Kumar CA. J. Pharm. Res., 2011; 4(1): pp 39-41.

16. Darak VR, Karadi AB, Arshad MD, Raj SA. Int. J. Pharm. Sci., 2011; 2(4): pp 31-35.

17. Reddy KS, Ramachandran B, NVS Naidu. Int. J. Sci. Eng. Res., 2014; 2(6): pp 52-56.

18. Rao KH, Rao AL, Sekhar KBC. Int. J. Res. Pharm. Chem., 2013; 3(2): pp 472-476. 